\title{
Effects of Free Radicals on Coronary Artery
}

\author{
Mandeep Walia ${ }^{b}$ Chiu-Yin Kwan ${ }^{a}$ Ashok K. Grovera, b \\ Departments of a Medicine and biology, McMaster University, Hamilton, Ont., Canada
}

\section{Key Words}

Oxidative stress · Ischaemia-reperfusion · Cardiac disorders - Vascular disease $\cdot$ Sarcoplasmic reticulum $\mathrm{Ca}^{2+}$ pump

\begin{abstract}
Coronary arteries supply blood to the heart and hence the control of coronary tone is pivotal to human survival. Reactive oxygen species (ROS) in specified amounts play an important role in normal metabolic and signalling processes. However, excess ROS can cause severe cardiovascular damage. For example, NO is produced by endothelium as a signal for relaxation. However, in an inflammatory response, NO from endothelium or macrophages can combine with superoxide to produce more deleterious peroxynitrite. Excess ROS have been associated with loss of coronary artery pliability - loss of contraction in some instances and relaxation in others. Atherosclerosis may also be considered an inflammatory response that leads to artery blockage, coronary disease and ischaemia-reperfusion. ROS produce various types of damage to ion channels and pumps and this damage is associated with vascular diseases such as atherosclerosis and hypertension. Endothelium and smooth muscle in the coronary artery are also affected differently by individual ROS. In fact, endothelium may act to protect the underlying smooth muscle against ROS. This review will give an overview of this field.
\end{abstract}

Copyright @2003S. Karger AG, Basel

\begin{tabular}{ll}
\hline KARGER & @ 2003 S. Karger AG, Basel \\
Fax +41613061234 $3471 / 03 / 0121-0001 \$ 19.50 / 0$ \\
$\begin{array}{l}\text { E-Mail karger@karger.ch } \\
\text { www.karger.com }\end{array}$ & $\begin{array}{l}\text { Accessible online at: } \\
\text { www.karger.com } / \mathrm{mpp}\end{array}$
\end{tabular}

\section{Introduction}

Coronary arteries supply the heart with oxygen and nutrients. Any obstruction in this flow may lead to a cardiac disorder and hence coronary tone is finely regulated. Several intrinsic factors and agents may act via endothelium or directly on smooth muscle and control the coronary tone. Examples are nitrates, cyclic nucleotides, $\mathrm{pO}_{2}$, $\mathrm{pCO}_{2}, \mathrm{pH}$, adenosine, $\mathrm{K}^{+}$, acetylcholine, 5-hydroxytryptamine, peptides and prostaglandins [1-4]. Actions of these agents affect cytosolic $\mathrm{Ca}^{2+}$ concentration $\left(\left[\mathrm{Ca}^{2+} \mathrm{i}\right]\right)$, which is key to regulation of the coronary tone. Thus mechanisms which influence $\left[\mathrm{Ca}^{2+}{ }_{\mathrm{i}}\right]$ via $\mathrm{Ca}^{2+}$ entry into or exit from the cells or the $\mathrm{Ca}^{2+}$ release or sequestration from internal sources may affect coronary artery contractility. The concentrations of individual ions across the plasma membrane (PM) of a cell are not at equilibrium and the cell membranes contain various transporters to control these non-equilibrium conditions. Abnormalities in the transporters may affect proper functioning of smooth muscle or endothelial cells. Control of $\left[\mathrm{Ca}^{2+}{ }_{i}\right]$ is pivotal to regulating actomyosin activity of smooth muscles. In the resting state $\left[\mathrm{Ca}^{2+}{ }_{\mathrm{i}}\right]$ is $\approx 0.1 \mu M$, but extracellular levels are greater than $1 \mathrm{~m} M$ and very high levels of $\mathrm{Ca}^{2+}$ are present in the sarco/endoplasmic reticulum (SR) [5]. In smooth muscle, a contraction may occur due to $\mathrm{Ca}^{2+}$ entry from the outside or by a release of $\mathrm{Ca}^{2+}$ from the SR. The contraction is controlled mainly by $\left[\mathrm{Ca}^{2+}{ }_{\mathrm{i}}\right]$ although it is also modulated by several factors. A number of mechanisms

Dr. A.K. Grove

Department of Medicine, McMaster University

Hamilton, Ont., L8N3Z5 (Canada)

Tel +1 905525 9140, ext. 22238, Fax + 19055223114

E-Mail groverak@fhs.csu.mcmaster.ca 
Fig. 1. Main mechanisms involved in the maintenance of the cytosolic free $\mathrm{Ca}^{2+}$ concentration in a vascular smooth muscle cell. Calcium homeostasis in the cytosol is maintained by $\mathrm{Na}^{+}-\mathrm{Ca}^{2+}$ exchanger. PM and SR $\mathrm{Ca}^{2+}$ ATPases. Calcium can enter the cell via VOCCs, $\mathrm{Na}^{+}-\mathrm{Ca}^{2+}$ exchanger, and $\mathrm{Ca}^{2+}$ leak channels. $\mathrm{P}_{\mathrm{i}}=$ Inorganic phosphate; $\left[\mathrm{Ca}^{2+}\right]_{\mathrm{e}}=$ extracellular free $\mathrm{Ca}^{2+}$ concentration; $\mathrm{R}=$ receptor.

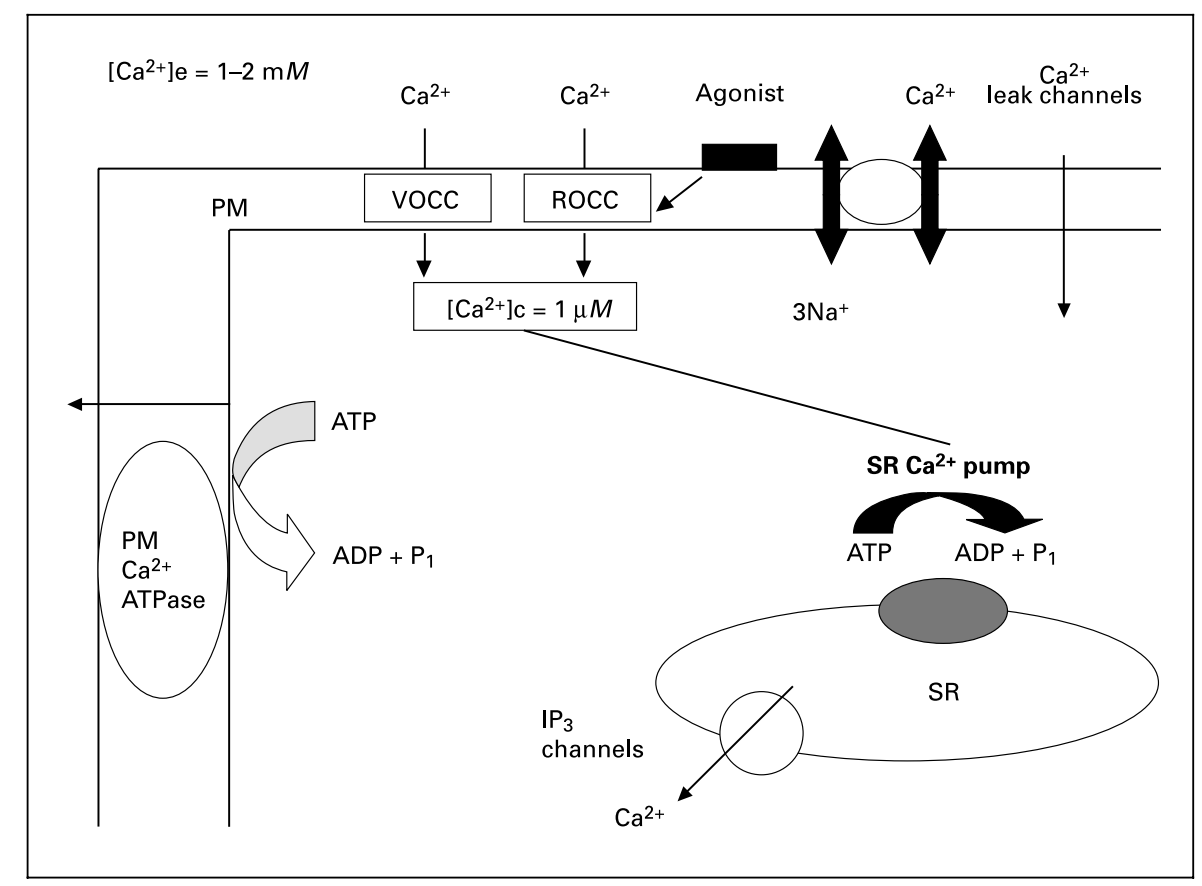

for $\mathrm{Ca}^{2+}$ entry including $\mathrm{Ca}^{2+}$ channels, and $\mathrm{Na}^{+}-\mathrm{Ca}^{2+}$ exchange have been identified [6]. In contrast to contraction, the relaxation depends on a restoration of $\left[\mathrm{Ca}^{2+}{ }_{i}\right]$ to the resting levels. The major relaxation mechanism appears to be removal of $\mathrm{Ca}^{2+}$ from the cytosol by $\mathrm{Ca}^{2+}$ pumps - one type present in the PM (PMCA pumps) and another in the SR (SERCA pumps) (fig. 1). Unlike the $\mathrm{Ca}^{2+}$ channels, the $\mathrm{Ca}^{2+}$ pumps can move $\mathrm{Ca}^{2+}$ against its electrochemical gradient by using the energy of hydrolysis of ATP. Major mechanisms for regulating $\left[\mathrm{Ca}^{2+}{ }_{\mathrm{i}}\right]$ include voltage-operated $\mathrm{Ca}^{2+}$ channels, $\mathrm{Na}^{+}-\mathrm{Ca}^{2+}$ exchange, PMCA pumps, SERCA pumps, and mechanisms for $\mathrm{Ca}^{2+}$ release from the $\mathrm{SR}$.

Local ischaemia or asphyxia due to interrupted respiration causes a compensatory vasodilation [7]. Prolonged ischaemia results in hypoxia and acidosis and may in turn lead to myocardial infarction. By far the most common cause of coronary artery disease is atherosclerosis, which is a progressive vascular disease with a manifestation of chronic heart failure and it can precipitate a myocardial infarction. Recent epidemiological studies have suggested an association between atherosclerosis and inflammation and infection [8]. This is in large part due to generation of excessive amounts of reactive oxygen species (ROS), which in turn cause the tissue damage [9]. Voltage-operated $\mathrm{Ca}^{2+}$ channels in the coronary artery smooth muscle are relatively resistant to ROS, but ATP-sensitive $\mathrm{K}^{+}$ channels have been reported to be more sensitive [10]. There are several reviews on ROS and their effects on various systems $[9,11,12]$. $\mathrm{Na}^{+}-\mathrm{K}^{+}-\mathrm{ATPase}$, an electrogenic $\mathrm{Na}^{+}$pump, is a major player in restoring membrane potential and intracellular $\mathrm{Na}^{+}$concentration and thus indirectly controls $\left[\mathrm{Ca}^{2+}{ }_{i}\right]$. This review focuses on the types of ROS produced during ischaemia-reperfusion and during inflammation and the ROS-induced damage in the coronary artery with special reference to the $\mathrm{Ca}^{2+}$ and $\mathrm{Na}^{+}$ pumps.

\section{Free Radicals and the Oxidant-Antioxidant Balance}

A free radical is an atom or a molecule containing one or more unpaired electrons in its outer orbit [9, 13, 14]. The major free radicals of interest in biological systems are those of oxygen. Often the term is used to include oxygen free radicals and other extremely ROS. ROS can be cationic, anionic or neutral. Since most ROS are membrane permeant, excessive ROS may cause oxidative damage to DNA, proteins, lipids and other components of the cell $[9,13-15]$. The unpaired electron of free radicals can be donated to cellular lipids and proteins to form peroxyl derivatives. This oxidation reaction may lead to changes in the nature of the lipids and proteins and ulti- 
mately cellular dysfunction. However, regulated amounts of ROS are formed in all aerobic organisms by enzymatic and non-enzymatic reactions. The dioxygen molecule physiologically undergoes successive reductions yielding the superoxide anion, hydrogen peroxide, and the hydroxyl radical [13] (fig. 2). Other ROS with an unpaired electron in their outer orbit are NO, lipid radicals, and lipid peroxides. Peroxynitrite and hydrogen peroxide are not radicals but are very biologically active. They may also be converted to much more active hydroxyl free radicals [9, 13].

ROS are normally present in very low concentrations in the body $\left(10^{-5}\right.$ to $\left.10^{-9} M\right)$. Physiologically, approximately $5 \%$ of the oxygen consumed by the tissue is converted into ROS [9]. There are endogenous enzymatic free radical scavengers present in the normal tissue such as catalase, superoxide dismutase and glutathione peroxidase that can detoxify basal levels of ROS $[9,13]$. Superoxide dismutase present in the mitochondria and the cytosol can catalytically accelerate the dismutation of superoxide anion to hydrogen peroxide and oxygen. Catalase present in peroxisomes can convert hydrogen peroxide to water and oxygen. Glutathione peroxidase can scavenge hydrogen peroxide as well as peroxyl radicals and peroxynitrite $[9,13]$. However, excessive production of ROS in pathological states can exceed the ability of endogenous anti-oxidant mechanisms to detoxify ROS. Excessive production of ROS is implicated in various pathologies such as myocardial ischaemia-reperfusion injury, inflammation, heart failure and atherosclerosis [11, 16].

\section{Sources of ROS in Physiological and Pathological States}

Under physiological conditions ROS can be generated in vivo by the mitochondrial electron transport chain, xanthine oxidase, neutrophils, nitric oxide synthase (NOS), NADPH oxidases and arachidonic acid metabolism [7, 9, 11, 13, 17]. Enhancement of one or more of these mechanisms may occur in pathological states.

Mitochondria are the main source of ROS in healthy cells where oxidation-reduction reactions occur and the metal-containing cytochromes are present [14]. The reduction of $\mathrm{O}_{2}$ and subsequent catalysis with superoxide dismutase form superoxide anion and peroxide by the donation of the electrons from either NADH dehydrogenase or ubiquinone cytochrome $b$ regions of the electron transport chain to molecular oxygen. Several ROS such as

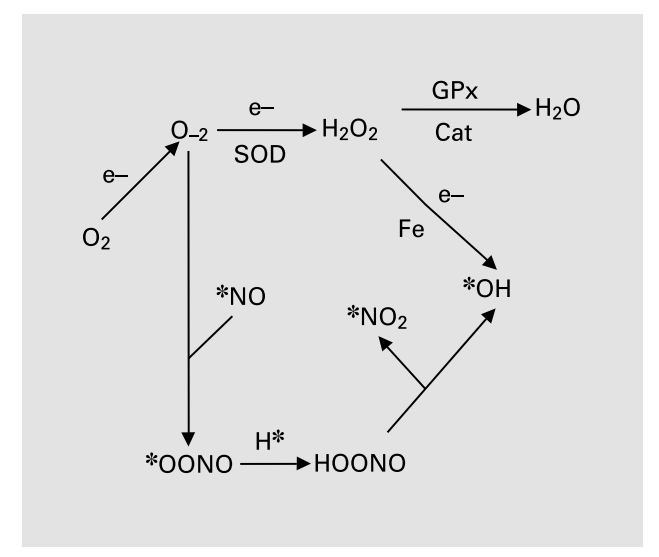

Fig. 2. Scheme showing ROS formed during the reduction of molecular oxygen $\left(\mathrm{O}_{2}\right)$ and interaction with ${ }^{*} \mathrm{NO}$ : superoxide anion $\left(\mathrm{O}_{2}{ }^{-}\right)$, hydrogen peroxide $\left(\mathrm{H}_{2} \mathrm{O}_{2}\right)$, hydroxyl radical $(* \mathrm{OH})$, NO radical $(* \mathrm{NO})$, peroxynitrite $\left({ }^{*} \mathrm{OONO}\right)$, and peroxynitrous acid (HOONO). $\mathrm{SOD}=$ Superoxide dismutase , Cat $=$ catalase, $\mathrm{GPx}=$ glutathione peroxidase.

superoxide anion, hydroxyl radical, and hydrogen peroxide can also be produced by stimulated neutrophils [15]. Excessive exposure of cells to ROS may itself produce oxidative damage, which can be generated following cell lysis, oxidative bursts (as part of the immune response) or by the presence of an excess of free transition metals [11, $12,14]$. NADPH oxidase is an enzyme that is located in the PM of endothelial and vascular smooth muscle cells and is an efficient source of superoxide anion [15, 18, 19]. Pathogens, cytokines, tissue hormones and physical forces activate NADPH oxidase [20]. It oxidizes NADPH on the cytoplasmic side and reduces $\mathrm{O}_{2}$ to superoxide on the exterior surface of the membrane [14]. ROS may also be produced upon stimulation of vascular smooth muscle cells. For example, the activity of NADPH oxidases and the formation of ROS in cultured vascular smooth muscle cells increase upon prolonged exposure to tumour necrosis factor alpha or angiotensin II [21]. The generation of ROS in the endothelium by xanthine oxidase may be a source during ischaemia or reperfusion injury [22]. $\mathrm{Ca}^{2+}$ dependent proteases which convert xanthine dehydrogenase to xanthine oxidase are activated by an increase in $\left[\mathrm{Ca}^{2+}{ }_{\mathrm{i}}\right]$ during ischaemic injury [22]. Xanthine oxidase in turn converts hypoxanthine to xanthine, uric acid, superoxide anion and hydrogen peroxide [14]. In arachidonic acid metabolism, cyclooxygenase catalyzes the oxidation of arachidonic acid to prostaglandin endoperoxide. ROS are also generated as a by-product when prostaglandin endoperoxide converts to other bioactive products [14]. 
Another potential source of vascular superoxide anion and NO is the endothelial NOS [12, 23]. Considerable amounts of superoxide may also be produced from the oxygenase domain of endothelial NOS in the absence of sufficient cofactors [23]. Both superoxide and NO are highly reactive and when in close proximity they react to form peroxynitrite. Peroxynitrite is only stable at basic $\mathrm{pH}$ and dissociates to form peroxynitrous acid, hydroxyl and nitrogen dioxide radicals at neutral $\mathrm{pH}[11,12]$.

In vascular biology, the abundance of ROS is very low for direct detection by electron spin resonance, but they can be trapped to form adducts, which may be subsequently characterized by this method [24]. ROS are highly reactive with short half-lives; one species may rapidly convert into another, and several species may coexist thereby making it very difficult to determine the exact nature of the ROS that produce a given effect. But in order to understand the mechanisms involved in the damage to the vascular system by oxidative stress, it is important to differentiate the nature and the amount of ROS involved. Therefore, experimentally, oxidative stress is usually produced by direct application of ROS such as hydrogen peroxide and peroxynitrite, through continuous ROS-generating agents such as nitric oxide donors (S-nitroso-N-acetyl penicillamine, 3-morpholinosydnonimine, hydrochloride, NONOates and S-nitroprusside) or ROS-generating enzymes such as xanthine oxidase for superoxide or glucose oxidase for hydrogen peroxide [11, $12,14]$. For example, in the absence of functional endothelium superoxide, hydroxyl free radicals and hydrogen peroxide can all cause contraction in rat aortic rings but with different patterns [25]. Superoxide generated using pyrogallol produces a phasic contraction followed by a smaller tonic contraction, whereas hydroxyl free radicals (generated by ascorbate/ $\mathrm{Fe}^{2+}$ system) cause comparable levels of phasic and tonic components, hydrogen peroxide gives primarily a phasic contraction. The species of the ROS involved in the aortic contraction was confirmed and identified with the selective ROS scavengers, such as superoxide dismutase (against superoxide anion), $\mathrm{DMSO} /$ mannitol (against hydroxyl free radicals) and catalase (against hydrogen peroxide).

\section{Cellular Damage by ROS}

ROS such as hydrogen peroxide, superoxide and hydroxyl radical can cause cellular damage. The damage may involve peroxidation of membrane and circulating lipids, oxidation of sulfhydryl groups in proteins, and damage to nucleic acids including DNA $[9,11,14,26]$. The lipids in the blood may be the most important target of free radical reactions as the oxidized lipids can travel throughout the circulatory system $[11,26]$. In turn they can oxidize lipids in the PM, thus increasing the PM permeability and causing the breakdown of transmembrane ion gradients. The consequence is the loss of secretory functions and inhibition of certain metabolic processes through a variety of reactions including amino acid oxidation and protein-protein cross-linking [26]. DNA damage caused by the ROS produced during normal cellular metabolism or under physiological stress may also contribute to mutation of critical target genes [12]. ROS cause both base damage and strand breaks in DNA. The alterations in the genome due to DNA damage can cause errors in transcription, mutations, recombinations and rearrangements [11]. Accumulation of mutations and deletions in mitochondrial DNA with their associated defects in oxidative phosphorylation may have implications in diabetes, ischaemic heart disease, Parkinson's disease, demyelinating polyneuropathy, cancer and aging $[11,12,14]$.

Of particular interest are the effects of peroxynitrite, which is a powerful oxidant formed during atherosclerotic inflammation and ischaemia-reperfusion from NO and superoxide. It has both physiological and cytotoxic effects. At low concentrations, like NO it induces vasodilation, inhibits platelet aggregation and leucocyte adhesion to the endothelium by both cGMP-dependent and independent pathways $[11,12,14]$. Peroxynitrite may exert its deleterious effects by oxidizing lipids, thiols, proteins and nucleic acids. The lipid peroxides and hydroperoxy radicals formed as a result may initiate the formation of other ROS. Peroxynitrite may adversely affect mitochondrial function. Inhibition of mitochondrial respiration by peroxide has been implicated in myocardial ischaemia-reperfusion injury and endotoxic shock. It can also inhibit Mndependent superoxide dismutase in the mitochondria by nitration of tyrosine residues, complex I, complex II and complex $\mathrm{V}$ by binding to the $\{\mathrm{Fe}-\mathrm{S}\}$ clusters of the enzymes $[12,14]$. It can oxidize mitochondrial proteins and membrane lipids that lead to the opening of the permeability transition pore to produce $\mathrm{Ca}^{2+}$ efflux. Peroxynitrite may damage DNA directly or by inhibiting DNA repair enzymes. The direct damage to DNA may occur by oxidation and nitration of DNA bases or by induction of nicks and breaks in DNA strands. Peroxynitrite may produce general damage by nitrosylation of tyrosine (free or protein-bound) to produce 3-nitrotyrosine. High plasma concentration of 3-nitrotyrosine is used as a specific biomarker for peroxynitrite [27]. Nitrosylated tyrosines in 
proteins affect protein structure and function. For example, nitrosylation of tyrosine kinases inhibits phosphorylation and thus tyrosine kinase-dependent downstream signalling is altered $[11,12]$. Thus peroxynitrite may affect a large number of cellular targets directly or via these signalling pathways.

\section{Cardiovascular Damage by ROS}

At low concentrations, ROS can serve as physiological signals but when in excess the same ROS may become toxic to the cells and precipitate pathophysiological events [28]. A typical example is NO. When released in small quantity from either vascular endothelium (via endothelial NOS) or non-sympathetic non-cholinergic nerves (via neuronal NOS) under normal physiological stimulus, NO lowers the arterial resistance and improves the blood flow. When produced in large quantities via the induction of inducible NOS by cytokines during inflammation, NO can collapse the circulatory system leading to shock and heart failure. Similarly, hydrogen peroxide is a cellular messenger produced in the signalling pathway of angiotensin II in vascular smooth muscle cells [18, 29, 30]. Also, at low concentrations, hydrogen peroxide can activate P2-purinoceptor in vascular smooth muscle [25]. Thus, at low concentrations, hydrogen peroxide may serve as a cellular messenger. In contrast, at high concentrations, it can cause cellular necrosis [31, 32]. This is why it is important that the concentrations of ROS be finely regulated by endogenous anti-oxidative mechanisms or managed clinically by exogenously administered anti-oxidants.

Excess ROS such as hydrogen peroxide, superoxide, peroxynitrite and hydroxyl anions are formed during myocardial ischaemia-reperfusion injury $[11,12,33]$. The injury involves several cell types including coronary endothelial cells, circulating blood cells (leucocytes, neutrophils, platelets) and cardiac myocytes. These cells show an increased ROS production in the diseased coronary artery. The ROS have the ability to injure vascular cells and cardiac myocytes directly [33]. In cardiac muscle, ROS may lower ATP production and thus decrease the ability of the $\mathrm{Ca}^{2+}$ pumps to function, thereby producing a $\mathrm{Ca}^{2+}$ overload [33]. The resulting $\mathrm{Ca}^{2+}$ overload may then result in contractile abnormalities.

Alloxan is a chemical used to damage the pancreatic cells via the formation of ROS. It induces experimental insulin-dependent diabetes mellitus and inhibits the ATP-dependent $\mathrm{Ca}^{2+}$ transport by microsomal mem- branes isolated from dog mesenteric arteries [34]. Preincubating the membranes with catalase (to degrade hydrogen peroxide) with and without superoxide dismutase (to remove superoxide anion) partially reverses the inhibition and additional reversal is achieved in the presence of mannitol to remove hydroxyl radicals. Preincubating the membranes with hydrogen peroxide also produces an inhibition of the $\mathrm{Ca}^{2+}$ uptake similar to that with alloxan. Furthermore, the inhibition of the $\mathrm{Ca}^{2+}$ uptake in these subcellular fractions by alloxan parallels those of PM markers and radioligand binding to adrenoceptors is also inhibited by alloxan $[35,36]$, suggesting that the site of action of ROS generated via alloxan auto-oxidation is the surface membranes. Furthermore, ROS-modified sulfhydryl groups have been attributed to the depression of other PM-associated proteins such as $\mathrm{Na}^{+}-\mathrm{K}^{+}$ATPase, $\mathrm{Na}^{+}-$ $\mathrm{Ca}^{2+}$ exchange and voltage-operated $\mathrm{Ca}^{2+}$ channels [33]. Although there are no reported studies on the direct effects of alloxan on coronary artery, one anticipates that the results would be similar.

\section{Inflammation and Coronary Artery Disease}

As noted earlier, the most common cause of progressive coronary artery disease during adult life is atherosclerosis, and an acute self-limited vasculitis that particularly affects the coronary arteries (Kawasaki disease) occurs predominantly in infants and young children. The atherosclerosis in adulthood may be associated with a number of risk factors, especially those associated with lifestyles, whereas Kawasaki disease in children has an unknown cause and produces coronary artery aneurysms in approximately $20 \%$ of those affected [37]. Therapy for Kawasaki disease in the acute phase is aimed at reducing inflammation of the coronary artery wall and preventing coronary thrombosis. The coronary artery atherosclerosis is also closely linked to inflammation and infection [8].

The classical concept of atherosclerotic lesion in the arterial wall has been a lipid disorder with excessive influx of lipids into the arterial wall, with macrophages contributing to the eventual lesion by scavenging the lipids. Currently, the major contributions relate to the role of intraplaque inflammation, with macrophages interacting with other inflammatory cells such as lymphocytes and mast cells. There is a direct relationship between the number of inflammatory cells, markers of inflammation and the severity of the coronary syndrome [38]. Furthermore, systemic infection and inflammation can also induce low density lipoprotein oxidation in vivo and promote athero- 
genesis, thus contributing to increased incidence of coronary artery disease in patients with inflammatory disorders [39].

Patients with an activated renin-angiotensin system are at increased risk of myocardial infarction [40]. Administration of ACE inhibitors decreases the risk, the acute coronary syndromes and the associated increased serum level of interleukin-6. Angiotensin II was identified in close proximity to the rupture site of human coronary arteries in acute myocardial infarction, and angiotensin II-induced synthesis and release of interleukin-6 appeared soon after stimulation in vitro in rat aortic smooth muscle. Angiotensin II-type 1 receptors and ACE were also found to be expressed at strategic sites of human atherosclerotic coronary plaques. These observations collectively suggest that this renin-angiotensin system may contribute to inflammatory processes within the vascular wall and to the development of acute coronary syndromes [40]. This hypothesis is also supported by the fact that treatment of patients with stable coronary artery disease using irbesartan, an angiotensin II-type 1 receptor antagonist, suppressed the expression of tumour necrosis factorvascular cell adhesion molecule-1 and superoxide, which are established markers of inflammation [41]. Elevated levels of angiotensin II may also be associated with the generation of oxidative stress, and may thus play a significant role in the early phase of atherosclerosis [42]. Acute coronary syndromes usually result from rupture of unstable atherosclerotic plaque mechanistically linked to the inflammatory process developed within the intima [43]. Thus, endothelium not only produces a number of vasodilators and vasoconstrictors to regulate vascular muscle tone, but also forms the template for the recruitment and activity of inflammatory cells contributing towards thrombosis. Oxidative stress increases the level of ROS and oxidized low density lipoprotein-cholesterol and impairs the membrane integrity of endothelial cells, thereby adversely affecting endothelial function. On the one hand, the endothelium SERCA is more resistant to the attack by ROS partly due to the different susceptibility of SERCA isoforms and partly due to the presence of high anti-oxidant potential (e.g., catalase level, see more detail in subsequent sections); on the other hand, the formation and release of lysophosphatidylcholine, which is the marker for oxidative modification of low density lipoprotein and renders several pro-atherogenic effects, has been shown to preferentially damage the vascular endothelial rather than smooth muscle cells, blunting the NO-release function and increasing the cell membrane permeability to ions, including $\mathrm{Ca}^{2+}[44]$.

\section{Actions of ROS on Pumps in Coronary Artery}

$\mathrm{Ca}^{2+}$ pumps may be broadly classified into $\mathrm{PM} \mathrm{Ca}^{2+}$ pumps (PMCA) and SR/ER $\mathrm{Ca}^{2+}$ pumps (SERCA). SERCA pumps are encoded by three different genes. The coronary artery smooth muscle expresses SERCA2 gene, predominantly the splice variant SERCA2b [45]. The effects of hydrogen peroxide have been reported on the $\mathrm{Ca}^{2+}$ pumps in the endothelium and smooth muscle of the coronary artery, but those of superoxide and peroxynitrite only on the smooth muscle.

\section{Coronary Artery Smooth Muscle}

In general, the SERCA pumps are more susceptible to ROS than are the $\mathrm{PM} \mathrm{Ca}^{2+}$ pumps [46-49]. The resistance is important as it allows the cells to survive as excessive extracellular $\mathrm{Ca}^{2+}$ would cause cell death. The ROSinduced damage to smooth muscle SERCA pumps in pig coronary artery leads to a decrease in $\mathrm{Ca}^{2+}$ sequestration and it results in an increase in $\left[\mathrm{Ca}^{2+}{ }_{\mathrm{i}}\right]$ [50]. Inactivation of the SERCA pump and its partial reactions has been shown in membranes isolated from coronary artery with hydrogen peroxide, superoxide and peroxynitrite [46-49]. The inactivation by superoxide may be prevented by competition with thiol reagents [47]. Such experiments are not possible with peroxide and peroxynitrite both of which react instantaneously with thiols. However, the addition of thiols after incubation of the membranes with peroxide or peroxynitrite does not reverse the inhibition, indicating that the inactivation of the pump involves more than a disulfide bond formation or S-nitrosylation [49]. Interestingly, incubation with either of these agents produces large covalently linked oligomers which may not be dissociable. The inactivation of SERCA pumps in smooth muscle results in decreased arterial pliability as the arteries show decreased contractions to angiotensin II and to the SERCA pump inhibitors thapsigargin and cyclopiazonic acid and to some extent to endothelins [50, 51]. Experiments using cells permeabilized with saponin allowed loading of $\mathrm{Ca}^{2+}$ into a pool only part of which was released with the inositol triphosphate even though all the loaded $\mathrm{Ca}^{2+}$ could be released with the $\mathrm{Ca}^{2+}$ ionophore A23187 [52]. Curiously, treating the cells with superoxide before the permeabilization inhibited loading by the SERCA pump into only the IP3-releasable component and that with peroxide inhibits loading into both. Thus there may be a heterogeneity in various $\mathrm{Ca}^{2+}$ pools loaded by SERCA2 in this tissue. A heterogeneity in SERCA2loaded pools has also been suggested in other tissues [53]. 
The $\mathrm{Na}^{+}$pump is a $\mathrm{Na}^{+}-\mathrm{K}^{+}$-ATPase that exports across PM $3 \mathrm{Na}^{+}$and imports $2 \mathrm{~K}^{+}$in each reaction cycle. Hydrogen peroxide does not affect the hydrolysis reaction of the pump but it uncouples it from its transport reaction [54, 55]. Proteases have been shown to produce similar uncoupling of the $\mathrm{Na}^{+}$pump in other tissues [56]. The uncoupling is a 'double whammy' for the coronary artery smooth muscle cell in ischaemia-reperfusion, which is already starved for ATP and now has a pump that keeps hydrolyzing ATP without improving ion homeostasis.

\section{Coronary Artery Endothelium}

Endothelium in this artery expresses the SERCA3 gene plus SERCA2 in contrast to smooth muscle that expresses only SERCA2. In HEK 293 cells overexpressing the SERCA pump proteins, the resistance to inactivation by hydrogen peroxide and superoxide is greater for the SERCA3 protein than for SERCA2 [57]. When cells cultured from the coronary artery are treated with peroxide, the resistance to hydrogen peroxide is even greater for the endothelial cells than for the smooth muscle cells than expected from the two tissues expressing different isoforms of SERCA [58]. This difference is also reflected when the effects of hydrogen peroxide are examined on contractility of the artery. The SERCA pump inhibitor cyclopiazonic acid contracts de-endothelialized arteries, but it relaxes precontracted arteries with intact endothelium. Peroxide treatment inhibits the contraction in the de-endothelialized arteries, but the endothelium-dependent relaxation is relatively resistant to this treatment. Similarly, cyclopiazonic acid produces a transient increase in intracellular $\mathrm{Ca}^{2+}$ in cultured cells. This increase in smooth muscle cells is inhibited by treating the cells with peroxide, but endothelial cells are resistant to this treatment [58]. The differences arise in part from a very high specific activity of catalase present in the endothelium compared to the smooth muscle [59].

\section{Endothelium Protects Underlying Smooth Muscle from ROS}

The presence of a high specific activity of catalase in the endothelium forces one to think that endothelium may be able to protect the underlying smooth muscle against luminal ROS. In a set of experiments, arteries were perfused either before removing the endothelium or after. The arteries were perfused with different concentrations of hydrogen peroxide and then washed. Endothelium was then removed from the arteries if not done so previously. All the arteries were then tested for their contraction to cyclopiazonic acid. Perfusion with peroxide decreased the force of contraction more if endothelium was removed before the perfusion than if it was removed after [59]. Thus endothelium protected the underlying smooth muscle against luminal peroxide. These preliminary data provide a very interesting model in which endothelium has an additional role of protecting the underlying smooth muscle against excess ROS. The model still needs to be fully tested. Firstly, what are the levels of antioxidant enzymes and other anti-oxidants in endothelium that can help the arteries under oxidative stress? Secondly, what is the effect of loss of endothelium either by itself in atherosclerosis or during percutaneous transluminal coronary angioplasty? Does this loss contribute to a high rate of recurrence of coronary artery block? Does the loss of endothelium contribute to rejection rates in grafting during coronary bypass surgery? How can the knowledge of the contribution of these processes in these diseases or procedures help us in preventing or treating them? For example, can gene therapy be developed to prevent recurrence of heart attacks by enabling the smooth muscle to increase its anti-oxidant ability? We hope that the knowledge of the effects of ROS on coronary artery function in health and disease can provide us with future therapies.

\section{Acknowledgements}

This work was supported by a Grant-in-Aid (grant T-4815) and a Career Investigator Award (to A.K.G.) from the Heart and Stroke Foundation of Ontario. 


\section{References}

1 Olanrewaju HA, Mustafa SJ: Effects of adenosine analogues on tension and cytosolic $\mathrm{Ca}^{2+}$ in porcine coronary artery. Am J Physiol 1996; 270:H134-H141.

2 Chilian WM: Functional distribution of alpha 1- and alpha 2-adrenergic receptors in the coronary microcirculation. Circulation 1991;84: 2108-2122.

3 Godfraind T: Evidence for heterogeneity of endothelin receptor distribution in human coronary artery. Br J Pharmacol 1993;110:12011205.

4 Cushing DJ, Cohen ML: Comparison of the serotonin receptors that mediate smooth muscle contraction in canine and porcine coronary artery. J Pharmacol Exp Ther 1992;261:856862.

5 Grover AK, Fomin VP, Samson SE: Angiotensin II contractions in coronary artery: Nature of receptors and calcium pools. Mol Cell Biochem 1994;135:11-19.

6 Missiaen L, Wuytack F, Raeymaekers L, De Smedt H, Droogmans G, Declerck I, Casteels $\mathrm{R}$ : $\mathrm{Ca}^{2+}$ extrusion across plasma membrane and $\mathrm{Ca}^{2+}$ uptake by intracellular stores. Pharmacol Ther 1991;50:191-232.

7 Drexler H, Hornig B: Endothelial dysfunction in human disease. J Mol Cell Cardiol 1999;31: 51-60.

8 Becker AE, de Boer OJ, van Der Wal AC: The role of inflammation and infection in coronary artery disease. Annu Rev Med 2001;52:289297.

9 Halliwell B: Antioxidants and human disease: A general introduction. Nutr Rev 1997;55: S44-S49.

10 Gross GJ, Auchampach JA: Role of ATP dependent potassium channels in myocardial ischaemia. Cardiovasc Res 1992;26:10111016.

11 Liaudet L, Soriano FG, Szabo C: Biology of nitric oxide signaling. Crit Care Med 2000;28: N37-N52.

12 Beckman JS, Koppenol WH: Nitric oxide, superoxide, and peroxynitrite: The good, the bad, and ugly. Am J Physiol 1996;271:C1424C1437.

13 Bergendi L, Benes L, Durackova Z, Ferencik M: Chemistry, physiology and pathology of free radicals. Life Sci 1999;65:1865-1874.

14 Beckman JS, Beckman TW, Chen J, Marshall PA, Freeman BA: Apparent hydroxyl radical production by peroxynitrite: Implications for endothelial injury from nitric oxide and superoxide. Proc Natl Acad Sci USA 1990;87:16201624.

15 Sanders SA, Eisenthal R, Harrison R: NADH oxidase activity of human xanthine oxidoreductase: Generation of superoxide anion. Eur J Biochem 1997;245:541-548.

16 Wang P, Zweier JL: Measurement of nitric oxide and peroxynitrite generation in the postischemic heart: Evidence for peroxynitrite-mediated reperfusion injury. J Biol Chem 1996; 271:29223-29230.
17 Dreher D, Junod AF: Differential effects of superoxide, hydrogen peroxide, and hydroxyl radical on intracellular calcium in human endothelial cells. J Cell Physiol 1995;162:147153.

18 Griendling KK, Minieri CA, Ollerenshaw JD, Alexander RW: Angiotensin II stimulates NADH and NADPH oxidase activity in cultured vascular smooth muscle cells. Circ Res 1994; 74:1141-1148.

19 Jones SA, O'Donnell VB, Wood JD, Broughton JP, Hughes EJ, Jones OT: Expression of phagocyte NADPH oxidase components in human endothelial cells. Am J Physiol 1996;271: H1626-H1634.

20 Howard AB, Alexander RW, Nerem RM, Griendling KK, Taylor WR: Cyclic strain induces an oxidative stress in endothelial cells. Am J Physiol 1997;272:C421-C427.

21 De Keulenaer GW, Alexander RW, UshioFukai M, Ishizaka N, Griendling KK: Tumor necrosis factor alpha activates a p22phoxbased NADH oxidase in vascular smooth muscle. Biochem J 1998;329:653-657.

22 Yokoyama Y, Beckman JS, Beckman TK, Wheat JK, Cash TG, Freeman BA, Parks DA: Circulating xanthine oxidase: Potential mediator of ischemic injury. Am J Physiol 1990;258: G564-G570.

23 Vasquez-Vivar J, Kalyanaraman B, Martasek P, Hogg N, Masters BS, Karoui H, Tordo P, Pritchard KA Jr: Superoxide generation by endothelial nitric oxide synthase: The influence of cofactors. Proc Natl Acad Sci USA 1998;95: 9220-9225.

24 Kuppusamy P, Wang P, Zweier JL, Krishna MC, Mitchell JB, Ma L, Trimble CE, Hsia CJ: Electron paramagnetic resonance imaging of rat heart with nitroxide and polynitroxyl-albumin. Biochemistry 1996;35:7051-7057.

25 Shen JZ, Zheng XF, Kwan CY: Differential contractile actions of reactive oxygen species on rat aorta: Selective activation of ATP receptor by $\mathrm{H}_{2} \mathrm{O}_{2}$. Life Sci 2000;66:PL291-PL296.

26 Hogg N, Kalyanaraman B: Nitric oxide and lipid peroxidation. Biochim Biophys Acta 1999; 1411:378-384

27 van der Vliet A, Eiserich JP, Kaur H, Cross CE, Halliwell B: Nitrotyrosine as biomarker for reactive nitrogen species. Methods Enzymol 1996;269:175-184

28 Finkel T: Oxygen radicals and signaling. Curr Opin Cell Biol 1998;10:248-253.

29 Griendling KK, Ushio-Fukai M: Reactive oxygen species as mediators of angiotensin II signaling. Regul Pept 2000;91:21-27.

30 Torrecillas G, Boyano-Adanez MC, Medina J, Parra T, Griera M, Lopez-Ongil S, Arilla E, Rodriguez-Puyol M, Rodriguez-Puyol D: The role of hydrogen peroxide in the contractile response to angiotensin II. Mol Pharmacol 2001;59:104-112.

31 Rhee SG: Redox signaling: Hydrogen peroxide as intracellular messenger. Exp Mol Med 1999; 31:53-59.
32 Sundaresan M, Yu ZX, Ferrans VJ, Irani K, Finkel T: Requirement for generation of $\mathrm{H}_{2} \mathrm{O}_{2}$ for platelet-derived growth factor signal transduction. Science 1995;270:296-299.

33 Kaneko M, Matsumoto Y, Hayashi H, Kobayashi A, Yamazaki N: Oxygen free radicals and calcium homeostasis in the heart. Mol Cell Biochem 1994;139:91-100.

34 Kwan CY, Beazley JS: Mechanism of inhibition by alloxan of ATP-driven calcium transport by vascular smooth muscle microsomes. J Bioenerg Biomembr 1988;20:517-531.

35 Kwan CY: The plasma-membrane component is the primary site of action of alloxan on ATP driven $\mathrm{Ca}^{2+}$ transport in vascular-muscle microsomal fractions. Biochem J 1988;254:293296.

36 Kwan CY, Sipos S, Gaspar V: Alloxan inhibits ligand binding to adrenoceptors of vascular smooth muscle microsomes. Biochem J 1990; 270:137-140.

37 Newburger JW: Kawasaki disease. Curr Trea Options Cardiovasc Med 2000;2:227-236.

38 Saadeddin SM, Habbab MA, Ferns GA: Markers of inflammation and coronary artery disease. Med Sci Monit 2002;8:RA5-12.

39 Memon RA, Staprans I, Noor M, Holleran WM, Uchida Y, Moser AH, Feingold KR, Grunfeld C: Infection and inflammation induce LDL oxidation in vivo. Arterioscler Thromb Vasc Biol 2000;20:1536-1542.

40 Schieffer B, Schieffer E, Hilfiker-Kleiner D, Hilfiker A, Kovanen PT, Kaartinen M, Nussberger J, Harringer W, Drexler H: Expression of angiotensin II and interleukin 6 in human coronary atherosclerotic plaques: Potential implications for inflammation and plaque instability. Circulation 2000;101:1372-1378.

41 Navalkar S, Parthasarathy S, Santanam N, Khan BV: Irbesartan, an angiotensin type 1 receptor inhibitor, regulates markers of inflammation in patients with premature atherosclerosis. J Am Coll Cardiol 2001;37:440-444.

42 Farmer JA, Torre-Amione G: The renin angiotensin system as a risk factor for coronary artery disease. Curr Atheroscler Rep 2001;3: 117-124.

43 Libby P: Coronary artery injury and the biology of atherosclerosis: Inflammation, thrombosis, and stabilization. Am J Cardiol 2000;86: $3 \mathrm{~J}-8 \mathrm{~J}$.

44 Leung YM, Xion Y, Ou YJ, Kwan CY: Perturbation by lysophosphatidylcholine of membrane permeability in cultured vascular smooth muscle and endothelial cells. Life Sci 1998;63:965-973.

45 Misquitta CM, Mack DP, Grover AK: Sarco/ endoplasmic reticulum $\mathrm{Ca}^{2+}$ (SERCA)-pumps: Link to heart beats and calcium waves. Cell Calcium 1999;25:277-290.

46 Grover AK, Samson SE, Fomin VP: Peroxide inactivates calcium pumps in pig coronary artery. Am J Physiol 1992;263:H537-H543. 
47 Grover AK, Samson SE: Protection of $\mathrm{Ca}$ pump of coronary artery against inactivation by superoxide radical. Am J Physiol 1989;256: C666-C673.

48 Grover AK, Samson SE: Effect of superoxide radical on $\mathrm{Ca}^{2+}$ pumps of coronary artery. Am J Physiol 1988;255:C297-C303.

49 Grover AK, Samson SE, Robinson S, Kwan CY: Effects of peroxynitrite on sarcoplasmic reticulum $\mathrm{Ca}^{2+}$ pump in pig coronary artery smooth muscle. Am J Physiol 2002;10.1152/ ajpcell.00382.2002.

50 Grover AK, Samson SE, Fomin VP, Werstiuk ES: Effects of peroxide and superoxide on coronary artery: ANG II response and sarcoplasmic reticulum $\mathrm{Ca}^{2+}$ pump. Am J Physiol 1995;269: C546-C553.
51 Elmoselhi AB, Grover AK: Peroxide sensitivity of endothelin responses in coronary artery smooth muscle: ET(A) vs. ET(B) pathways. Mol Cell Biochem 1999;202:47-52.

52 Elmoselhi AB, Samson SE, Grover AK: SR $\mathrm{Ca}^{2+}$ pump heterogeneity in coronary artery: Free radicals and IP3-sensitive and -insensitive pools. Am J Physiol 1996;271:C1652-C1659.

53 Gill DL, Ghosh TK, Bian J, Short AD, Waldron RT, Rybak SL: Function and organization of the inositol 1,4,5-trisphosphate-sensitive calcium pool. Adv Second Messenger Phosphoprotein Res 1992;26:265-308.

54 Elmoselhi A, Butcher A, Samson SE, Grover AK: Coronary artery contractility, $\mathrm{Na}(+)$-pump and oxygen radicals. Gen Physiol Biophys 1994;13:247-256.

55 Elmoselhi AB, Butcher A, Samson SE, Grover AK: Free radicals uncouple the sodium pump in pig coronary artery. Am J Physiol 1994;266: C720-C728.
56 Harvey WJ, Blostein R: Uncoupling the red cell sodium pump by proteolysis. J Biol Chem 1986;261:1724-1729.

57 Grover AK, Samson SE, Misquitta CM: Sarco(endo)plasmic reticulum $\mathrm{Ca}^{2+}$ pump isoform SERCA3 is more resistant than SERCA2b to peroxide. Am J Physiol 1997;273:C420-C425.

58 Grover AK, Samson SE: Peroxide resistance of ER $\mathrm{Ca}^{2+}$ pump in endothelium: Implications to coronary artery function. Am J Physiol 1997; 273:C1250-C1258.

59 Grover AK, Hui J, Samson SE: Catalase activity in coronary artery endothelium protects smooth muscle against peroxide damage. Eur J Pharmacol 2000;387:87-91. 